\title{
Foreword: International Space Science Institute (ISSI) Workshop on the Earth's Hydrological Cycle
}

\author{
Lennart Bengtsson
}

Received: 6 November 2013/ Accepted: 7 November 2013/Published online: 13 December 2013

(C) Springer Science+Business Media Dordrecht 2013

Water is a central component in the Earth's system. It is indispensable for life on Earth in its present form and influences virtually every aspect of our planet's life support system. On relatively short time scales, atmospheric water vapor interacts with the atmospheric circulation and is crucial in forming the Earth's climate zones that determine where habitable areas can exist. On the longest time scales of hundreds of millions of years, water contributes to the lubrication of the movements of the tectonic plates, creating a pattern of change that has shaped and is continuing to shape the Earth.

In the atmosphere, water vapor plays a key role in the Earth's energy balance and regulates the Earth's climate in a significant way. Water vapor is the most powerful of the greenhouse gases and serves to enhance the tropospheric temperature because water vapor is physically and dynamically controlled by atmospheric temperature and atmospheric circulation. The total amount of available water on the Earth amounts to some $1.5 \times 10^{9} \mathrm{~km}^{3}$. The dominant part of this, $1.4 \times 10^{9} \mathrm{~km}^{3}$, resides in the oceans. About $29 \times 10^{6} \mathrm{~km}^{3}$ are locked up in the land ice on Greenland and Antarctica, and some $15 \times 10^{6} \mathrm{~km}^{3}$ are estimated to exist as groundwater. If all the ice over the land and all the glaciers were to melt, as has happened several times in the Earth's history, the sea level would rise by some $80 \mathrm{~m}$. In comparison, the total amount of water vapor in the atmosphere is small; it amounts to $\sim 2.5 \mathrm{~kg} / \mathrm{m}^{2}$, or the equivalent of $25 \mathrm{~mm}$ water for each column of air. Yet atmospheric water vapor is crucial for the Earth's energy balance.

The annual mean global values of evaporation and precipitation are $\sim 1,000 \mathrm{~mm}$ of water $/ \mathrm{m}^{2}$. However, these values vary enormously in space and time from areas that are almost completely dry to areas where the annual precipitation is more than an order of magnitude larger than the global mean value. An evaporation of 1,000 mm of water/year corresponds to $80 \mathrm{~W} / \mathrm{m}^{2}$ in energy loss for the surface and a corresponding gain for the atmosphere when condensation takes place. This is the single largest component for heating the atmosphere; it is even larger than the direct solar energy absorbed by the

\footnotetext{
L. Bengtsson $(\bowtie)$

Environmental Systems Science Centre, University of Reading, Reading, West Berkshire RG6 6UR, UK

e-mail: lennart.bengtsson@zmaw.de; lennart.bengtsson@mpimet.mpg.de
} 
atmosphere. This statement highlights the importance of the hydrological cycle for the energy balance the atmosphere.

As water vapor is also an effective absorber of terrestrial radiation, it contributes significantly to the regulation of the temperature of the lower atmosphere. The greenhouse effect of water vapor is estimated to be $\sim 24{ }^{\circ} \mathrm{C}$. However, water vapor has a residence time of 7-8 days in the atmosphere and responds effectively to temperature through the Clausius-Clapeyron (CC) relation. In the present situation, it is the increase of the longlasting greenhouse gases, namely $\mathrm{CO}_{2}, \mathrm{CH}_{4}, \mathrm{~N}_{2} \mathrm{O}$ and the CFCs, that are the drivers of climate change while water vapor generally acts as a positive feedback factor (Lacis et al. 2013). This is a fundamental factor in climate change. Model simulations suggest that water vapor feedback can more than double the initial effect of the long-lasting greenhouse gases.

With a population that has increased more the fourfold over the last 100 years and with an infrastructure that has grown by more than a factor of ten, society at large has become more exposed, in particular, to extremes in precipitation with associated flooding damages. Society has also over time significantly increased the amount of water that is needed, primarily for agriculture as well as for different kinds of industrial usage. This has contributed to a severe lack of water in exposed regions, even affecting major water bodies such as the Aral Sea and Lake Chad that have almost dried up completely during the last decades because of excessive extraction of water.

Other potential problems are disruptions related to climate change. The most severe prospects are systematic changes in weather zones such as a tendency for a poleward shift of the extra-tropical storm tracks that is indicated in climate simulation studies; others are the likelihood of more intense precipitation that will increase severe flooding. The poleward shift of weather systems is expected to create regional water problems with increased precipitation in some areas and decreased precipitation in other regions. Most severe here are the increasing risks of persistent periods of droughts, preferentially in the subtropics of both hemispheres (IPCC 2013).

In summary, society will have to cope with a multitude of disruptive events related to the water cycle due both to natural and anthropogenic effects such as (1) extreme events of heavy and persistent precipitation as well as extended periods of drought, which are all possible within the present climate, (2) anthropogenic actions unrelated to weather and climate, such as large-scale environmental changes caused by changing practices in largescale agriculture and forestry, and (3) changes in the water cycle as a consequence of climate change. Presently the first two are dominant but gradually, as the climate system is getting warmer, the third factor is expected to be of increasing importance.

A scientific assessment of the Earth's hydrological cycle is a complex task which covers a multitude of areas and applications. The scientific papers in the present volume address a broad area of research related to the Earth's Hydrological Cycle. They represent the outcome of the third workshop within the ISSI Earth's Science Programme. The workshop took place from 6 to 10 February, 2012, in Bern, Switzerland, with the objective of providing an in-depth overview of the Earth's hydrological cycle. The participants in the workshop were experts in a wide range of disciplines; they included geophysicists, meteorologists, hydrologists, oceanographers and climate modelers.

The increase in the world's population and the increasing need for food, energy and natural resources have put increasing stress on the water requirements.

Perhaps the most extreme effect of such a water stress is the almost complete destruction of the world's previously fourth largest lake, the Aral Sea. This is one of the planet's worst environmental disasters. Over a period of some 40 years, the lake has lost 
more than $90 \%$ of its area. The most likely reason for this is the massive agricultural developments that have used more and more of the water in the catchment areas of the Amu Darya and Syr Darya (Asokan and Destouni 2014).

As the extreme opposite effect, excessive flooding in rivers and in coastal areas is causing significant economic costs and hardship to their populations. Two kinds of events stand out. The first is mostly coupled to excessive precipitation in river catchments. This occurs over all continents during the rainy season, often with devastating consequences. The main cause is not necessarily higher precipitation but enhanced exposure to heavy precipitation mainly due to increased population and increased occupation in exposed areas. The second most important cause is related to coastal flooding that occurs in relation to intense weather systems, in particular tropical cyclones. The coastal flooding in New Orleans in 2005 and in New York in 2012 are prime examples of such events. Fortunately due to the advances made in weather prediction in recent decades, the public was warned several days in advance and evacuated the areas most at risk.

There is overwhelming evidence from theory (Held and Soden 2006, Stevens and Bony 2013) and from empirical and model studies (e.g., Allan 2014) that the atmospheric water vapor content increases with increasing temperature since it varies according to the $\mathrm{CC}$ relation. It also follows from theory that the horizontal transport of water vapor also scales with the CC. This is a serious consequence, as it will affect regional precipitation; in areas of convergence (such as the tropical convergence zone and at high latitudes), there will be increased precipitation. Alternatively, it will also affect areas of divergence (such as the subtropical regions), with the consequence of reduced precipitation. This response of the water cycle to climate warming is probably one of the most severe consequences of climate change, as it will amplify the extremes of the hydrological cycle. So far, because of the large variability of precipitation in time and space, we are not yet able to show this from observations but model results demonstrate this response clearly (e.g., Bengtsson 2011).

Even ocean circulation is affected as heavy precipitation will reduce salinity and thus diminish ocean convection. And, in an analogous way, reduced precipitation over ocean areas will increase salinity and increase ocean convection. Observations from ESA's Soil Moisture and Ocean Salinity satellite (SMOS) are providing new and exciting knowledge (Reul et al. 2014) in this area. There is a wide range of methodological studies, mainly related to the handling of the water cycle in climate models due to the fine structure of precipitation processes in the atmosphere that present climate models cannot handle very well (Foufola-Giorgiou 2014). Both satellite and ground-based radar information are of special importance here and highlight the need for higher resolution in weather and climate models.

\section{References}

Allan R (2014) Physically consistent responses of the global atmospheric cycle in models and observations. Surv Geophys (this issue)

Asokan S, Destouni G (2014) Irrigation effects on hydro-climatic change: basin-wide water balance-constrained quantification and cross-regional comparison. Surv Geophys (this issue)

Bengtsson L (2011) The global atmospheric water cycle, Environ Res Lett, 5:025001 (8 pp) doi:10.1088/ $1748-9326 / 5 / 2 / 025001,2010$

Foufola-Giorgiou E (2014) Downscaling satellite precipitation with emphasis on extremes, Surv Geophys (this issue)

Held I, Soden B (2006) Robust response of the hydrological cycle to global warming. J Climate 19:5686-5699 
Intergovernmental Panel on Climate Change, IPCC (2013), Climate Change 2013: the physical science basis, Working Group I Contribution to the IPCC Fifth Assessment Report

Lacis A, Hansen J, Jonas J, Oinas V, Russell G (2013) The role of long-lived greenhouse gases as principal LW control knob that governs the global surface temperature for past and future climate change. Tellus (accepted)

Reul N, Fournier S, Boutin J, Hernandes O, Maes C, Chapron B, Alory G, Quilfen Y, Tenerelli J, Morisset S, Kerr Y, Mecklenburg S, Delwart S (2014) Sea surface salinity observations from space with SMOS satellite: new tool to better monitor the marine branch of the water cycle. Surv Geophys (this issue)

Stevens B, Bony S (2013) What are climate models missing? Science 340:1053-1054 